\title{
New Approach of Highly Efficient Fermentation Process for Bioethanol using Xylose as Agriculture Residues
}

\author{
Abu Saleh Ahmed ${ }^{1 *}$, Seiya Watanabe ${ }^{2}$, Sinin Hamdan ${ }^{1}$, Tsutomu Kodaki ${ }^{2}$, and Keisuke \\ Makino $^{2}$
}

From 1. Faculty of Engineering, Universiti Malaysia Sarawak, 94300 Kota Samarahan, Sarawak, Malaysia, 2. Institute of Advanced Energy, Kyoto University, Gokasho, Uji, Kyoto 611-0011, Japan,

* To whom correspondence should be addressed:

Corresponding author:

Faculty of Engineering

Universiti Malaysia Sarawak

94300 Kota Samarahan

Sarawak, Malaysia

Tel: $+60-82-583299$

Fax: $+60-82-583410$

E-mail: aasaleh@feng.unimas.my

(Keywords: agricultural waste biomass, protein engineering, xylitol dehydrogenase, xylosefermentation, ethanol production) 


\section{ABSTRACT}

Agricultural waste biomass has already been transferred to bioethanol and used as energy related products, although many issues such as efficiency and productivity still exist to be overcome. In this study, the protein engineering was applied to generate enzymes with completely reversed coenzyme specificity and developed recombinant yeasts containing those engineered enzymes for construction of an efficient biomass-ethanol conversion system. Recombinant yeasts were constructed with the genes encoding a wild type xylose reductase (XR) and the protein engineered xylitol dehydrogenase (XDH) (with NADP) of Pichia stipitis. These recombinant yeasts were characterized based on the enzyme activity and fermentation ability of xylose to ethanol. The protein engineered enzymes were expressed significantly in Saccharomyces cerevisiae as judged by the enzyme activity in vitro. Ethanol fermentation was measured in batch culture under anaerobic conditions. The significant enhancement was found in Y-ARS strain, in which $\mathrm{NADP}^{+}$-dependent $\mathrm{XDH}$ was expressed; $85 \%$ decrease of unfavorable xylitol excretion with $26 \%$ increased ethanol production, when compared with the reference strain expressing the wild-type XDH.

\section{INTRODUCTION}

The more efficient use of biomass is demanded to solve the global crisis such as depletion of fossil fuel and global warming. Woody biomass, including agriculture residues, wood chips, municipal solid wastes, paper wastes, etc., has already been transferred to bioethanol and biodiesel in some cases and used as energy related products, although many issues such as efficiency and productivity still exist to be overcome. Xylose is one of the major fermentable sugars present in lignocellulosic biomass, the second most abundant carbohydrate polymer in nature to glucose. The efficient fermentation of xylose is required to develop economically viable processes for producing biofuels such as ethanol from biomass [1]. Although a few xylose fermenting yeasts are found in nature [2, 3], Saccharomyces cerevisiae is used universally for industrial ethanol production because of the ability to produce high concentrations of ethanol and high inherent ethanol tolerance. Although the native $S$. cerevisiae can not ferment xylose, the $S$. cerevisiae transformed with the native enzymes encoding xylose reductase (XR) and xylitol dehydrogenase (XDH) from Pichia stipitis, a most potent recombinant strain, acquires the ability to ferment xylose to ethanol [4, 5]. So engineering for xylose utilization has been focused on adapting the xylose metabolic pathway from the xylose-utilizing yeast Pichia stipitis. In this organism, xylose is converted into xylulose by two oxidoreductases. First, xylose is reduced to xylitol by an NADPH/NADHlinked xylose reducatase (XR) [6], and then xylitol is oxidized to xylulose by an NAD-linked xylitol dehydrogenase (XDH) [7]. Finally, xylulokinase (XK) phosphorylates xylulose into xylulose-5-phosphate, which is metabolized further via the pentose phosphate pathway (PPP) (Fig. 1). Many researchers attempt at engineering xylose metabolism expressed only native $\mathrm{XR}$ and XDH from P. stipitis in S. cerevisiae because S. cerevisiae can ferment xylulose [8]. Recombinant $S$. cerevisiae expressing native $\mathrm{XR}$ and $\mathrm{XDH}$ could grow on xylose, but ethanol production from xylose was not significant because a substantial portion of the consumed xylose was converted into xylitol [9].

The most straightforward metabolic engineering strategy is the expression of bacterial xylose isomerase (XI) gene, so that xylose can directly be converted to xylulose with no coenzyme. There have been numerous unsuccessful attemts to express XI genes from various bacteria in $S$. cerevisiae except a thermophilic enzyme [10,11], we focused on the fungal xylose metabolic pathway in this study. XR and XDH in this fungal pathway are necessary for 
S. cerevisiae to ferment xylose to ethanol because of a lack of genes encoding these enzymes in $S$. cerevisiae. Several studies reported that $S$. cerevisiae transforming the genes encoding $\mathrm{XR}, \mathrm{XDH}$ from $P$. stipitis and the endogenous gene $\mathrm{XK}$, a most potent recombinant strain, has not yet been applied to the industrial bio-process due to the unfavorable excretion of xylitol $[12,13]$. Because intercellular redox imbalance caused by the different coenzyme specificity of XR (with NADPH) and XDH (with NAD) has been thought to be one of the main factors of xylitol excretion. The introduction of the protein engineered XDH (with NADP) of $P$. stipitis generated in this study prevented this xylitol excretion by maintaining the intercellular redox balance.

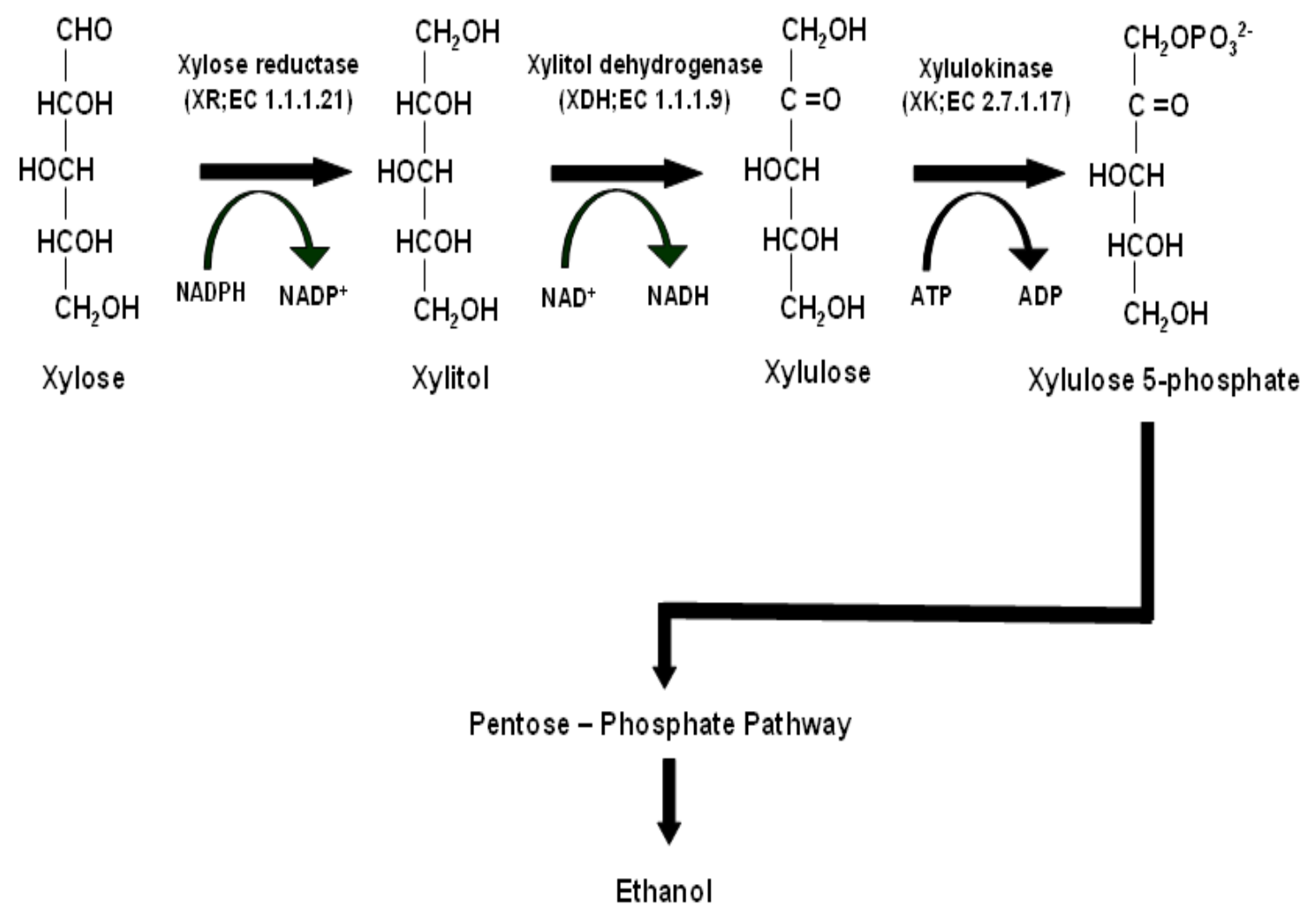

Figure 1 Metabolic pathway from xylose to ethanol

In spite of many attempts for modification of coenzyme specificity, only a few of them can be judged to be fully reversal, in terms of obtaining a mutant enzyme as catalytically efficient as the wild type $[14,15]$. In our previous study [16], site-directed mutagenesis for complete reversal of coenzyme specificity was performed on $\mathrm{NAD}^{+}$-dependent $\mathrm{XDH}$ from $P$. stipitis to generate $\mathrm{NADP}^{+}$dependent $\mathrm{XDH}$ and these mutated $\mathrm{XDHs}$ were characterized in vitro. In the present study, we constructed recombinant yeasts that were transformed with the genes encoding the protein engineered XDH (with completely NADP-dependent) and a wild type $\mathrm{XR}$ of $P$. stipitis and characterized those recombinant yeasts based on the enzyme activity and fermentation ability of xylose to ethanol. The protein engineered enzymes were expressed significantly in $S$. cerevisiae as judged by the enzyme activity in vitro. Ethanol fermentation was measured in batch culture under anaerobic conditions. Introduction of NADP-dependent $\mathrm{XDH}$ was shown to prevent the xylitol excretion probably because of maintaining the intercellular redox balance. 


\section{MATERIALS AND METHODS}

\subsection{Materials and Media}

S. cerevisiae D452-2 (MATa leu2 his3ura3can1) [17] was used as the recipient yeast strain for the expression of Pichia stipitis XDH and XR. S. cerevisiae was grown in YPD medium (10 g/l yeast extract, $20 \mathrm{~g} / \mathrm{l}$ peptone, and $20 \mathrm{~g} / \mathrm{l}$ glucose) for transformation. In all other experiments, a defined minimal medium $(6.7 \mathrm{~g}$ of yeast nitrogen base without amino acid with $5 \mathrm{~g}$ glucose per liter) was used. Leucine, Histidine, and Uracil were added at 20 $\mathrm{mg} / \mathrm{l}, 20 \mathrm{mg} / \mathrm{l}$, and $5 \mathrm{mg} / \mathrm{l}$ respectively for strain D452-2. Bacterial strains were grown in Luria-Bertani medium (yeast extract $5 \mathrm{~g} / \mathrm{l}$, peptone $10 \mathrm{~g} / \mathrm{l}$, and sodium chloride $10 \mathrm{~g} / \mathrm{l}$ ). Transformants were selected by adding ampicillin $(50 \mathrm{mg} / \mathrm{liter})$. For growth on solid media 20 $\mathrm{g}$ of agar per liter was added.

\subsection{Yeast Strain Transformation}

Yeast transformation was performed using the lithium acetate method [18]. Yeast cells were incubated overnight in YPD medium before being streaked on selective medium. $S$. cerevisiae transformants were selected on agar plates with minimal medium containing 20 $\mathrm{mg} / \mathrm{l}$ histidine, $20 \mathrm{mg} / \mathrm{l}$ leucine and $5 \mathrm{mg} / \mathrm{l}$ uracil.

\subsection{Preparation of Crude cell Extract}

The recombinant yeast strains were grown in minimal medium at $30^{\circ} \mathrm{C}$. The cells were harvested by centrifugation at $5000 \mathrm{rpm}$ for 10 minutes. The cells were resuspended in disintegration buffer $100 \mathrm{mM}$ sodium phosphate ( $\mathrm{pH}$ 7.0) containing $1 \mathrm{mM} \mathrm{MgCl} 2,0.5 \mathrm{mM}$ EDTA and $0.5 \mathrm{mM}$ dithiothreitol (DTT) and vortexed together with an equal volume of glass beads $(0.5 \mathrm{~mm}$ diameter $)$ twice for $5 \mathrm{~min}$ at $4^{\circ} \mathrm{C}$. Cell debris and glass beads from the cell extract were separated by centrifugation at $15000 \mathrm{rpm}, 10 \mathrm{~min}, 4^{\circ} \mathrm{C}$ and the remaining supernatant was used for enzyme determinations.

\subsection{Enzyme Assays}

Enzyme activities were measured by using a V-550 model spectrophotometer (JASCO Corporation, Japan) operating at $340 \mathrm{~nm}$ and $35^{\circ} \mathrm{C}$. The standard assay mixture for $\mathrm{XDH}$ contained $50 \mathrm{mM} \mathrm{MgCl} 2$ and $300 \mathrm{mM}$ xylitol in $50 \mathrm{mM}$ Tris- $\mathrm{HCl}$ (pH 9.0); for XR contained $60 \mathrm{mM}$ sodium phosphate and $133 \mathrm{mM}$ xylose [13]. All reactions were started by addition of $0.10 \mathrm{ml}$ of a $20 \mathrm{mM}$ NAD/NADP solution for XDH and $0.10 \mathrm{ml}$ of a $1.5 \mathrm{mM} \mathrm{NADPH} / \mathrm{NADH}$ solution for $\mathrm{XR}$ to a final volume of $1.0 \mathrm{ml}$ (standard assay condition). One unit of enzyme activity refers to $1 \mu \mathrm{mol}$ of $\mathrm{NAD}(\mathrm{P})^{+} \mathrm{H}$ produced $/ \mathrm{min}$. Protein concentrations were determined by the method of Lowry et al. [19] with bovine serum albumin as a standard.

\subsection{Preliminary Batch Fermentation in Shake Flask}

After precultivation of recombinant yeast strains in $3 \mathrm{ml}$ minimal medium in $15 \mathrm{ml}$ falcon tube for 3 days, yeast cells were aerobically cultivated for 3 days at $30^{\circ} \mathrm{C}$ in $100 \mathrm{ml}$ minimal medium in $300 \mathrm{ml}$ flask in incubator at $200 \mathrm{rpm}$. The cell pellets were collected by centrifugation for $10 \mathrm{~min}$ at $5000 \mathrm{rpm}$ and $4^{\circ} \mathrm{C}$, and were washed once with a solution containing $9 \mathrm{~g}$ of $\mathrm{NaCl} / \mathrm{liter}$. The cell pellets were then inoculated into $200 \mathrm{ml}$ fermented medium $(6.7 \mathrm{~g}$ of yeast nitrogen base without amino acid per liter with $5 \mathrm{~g}$ of glucose/liter 
plus $15 \mathrm{~g}$ of xylose/liter and appropriate amino acid). Ethanol fermentation was carried out as batch cultures in $200 \mathrm{ml}$ flask with anaerobic condition in incubator at $150 \mathrm{rpm}$. The flasks were sealed with two layers of Saran wrapping paper to allow fermentation to occur anaerobically. Samples $(1 \mathrm{ml})$ of the fermentation broth were removed at intervals and stocked at $-35^{\circ} \mathrm{C}$ for analyses of substrates and fermentation products.

\subsection{Batch Fermentation in Bioreactor}

A high performance bioreactor (BioFlo 110, New Brunswick Scientific Co.) was used for anaerobic batch fermentation. After precultivation of recombinant yeast strains in $5 \mathrm{ml}$ minimal medium in $15 \mathrm{ml}$ falcon tube for 3 days, yeast cells were aerobically cultivated for 3 days at $30^{\circ} \mathrm{C}$ in $300 \mathrm{ml}$ minimal medium in 1 liter flask in incubator at $200 \mathrm{rpm}$. The cell pellets were collected by centrifugation for $10 \mathrm{~min}$ at $5000 \mathrm{rpm}$ and $4^{\circ} \mathrm{C}$, and were washed once with a solution containing $9 \mathrm{~g}$ of $\mathrm{NaCl} /$ liter. The cell pellets were then inoculated into fermented medium (6.7 $\mathrm{g}$ of yeast nitrogen base without amino acid per liter with $5 \mathrm{~g}$ of glucose/liter plus $15 \mathrm{~g}$ of xylose/liter and appropriate amino acid). Silicone antifoam 0.5 $\mathrm{ml} / \mathrm{liter}$ was added to the media before autoclaving. Anaerobic cultivation took place in a 1.3 liter bioreactor with an initial working volume 1 liter. The temperature was maintained at $30^{\circ} \mathrm{C}$. The $\mathrm{pH}$ was controlled at 5.5 by addition of $2 \mathrm{M} \mathrm{NaOH}$ and $1 \mathrm{M} \mathrm{H}_{2} \mathrm{SO}_{4}$. The agitation speed was constant at $500 \mathrm{rpm}$.

\subsection{Analysis of Fermentation Products}

Ethanol concentration was measured using gas chromatography. The gas chromatograph (model GC -14B, Shimadzu Corporation, Kyoto, Japan, fitted with a flame ionization detector) was operated under the following conditions: glass column $(2.0 \mathrm{~m}$ by $3.2 \mathrm{~mm})$ packed with Thermon-3000 (Shimadzu); temperature of column $70^{\circ} \mathrm{C}$, injector $200^{\circ} \mathrm{C}$, and detector $250^{\circ} \mathrm{C}$; and nitrogen carrier gas flow rate $25 \mathrm{ml} / \mathrm{min}$. A high-performance liquid chromatograph (Tosoh Corporation Ltd., Japan) equipped with an RI detector was used to analyze the concentrations of glucose, xylose, xylitol, glycerol, and acetic acid. A Bio-Rad type HPX-87H ion-exclusion column was used. The mobile phase was $5 \mathrm{mM} \mathrm{H}_{2} \mathrm{SO}_{4}$ at a flow rate of $0.4 \mathrm{ml} / \mathrm{min}$. Cell growth was monitored by measuring the absorbance at $600 \mathrm{~nm}$ using a spectrophotometer (model U-2001, Hitachi, Japan).

\section{RESULTS AND DISCUSSION}

\subsection{Expression of $P$. stipitis $\mathrm{XR}$ and XDH mutants in $S$. cerevisiae}

Plasmids pPGK-WT and pPGK-ARS for XDH expression in yeast were constructed by inserting the wild-type (WT) or corresponding mutated XDH expression region [16] into a yeast expression vector, pPGK [20], which is a $2 \mu \mathrm{m}$ DNA-based shuttle vector containing a phosphoglycerate kinase (PGK) promoter and terminator for expression, a multicloning site, and the URA3 gene as a yeast selectable marker (Fig. 2). To construct a plasmid for XR expression in yeast, the XR coding region [21] was first inserted into pPGK vector. Then the XR coding region with PGK promoter and terminator was excised from the plasmid and reinserted into YEpM4 [22] vector, which is a $2 \mu \mathrm{m}$ DNA-based shuttle vector containing a multicloning site LEU2 gene as a yeast selectable marker (Fig. 3) to yield pPGK-XR. $S$. cerevisiae D452-2 (MATa leu2 his3ura3canl) [17] was used as the recipient yeast strain for the expression of XDH and XR. D452-2 was transformed with pPGK-XR and then D452-2 
containing pPGK-XR was further transformed with pPGK-WT and pPGK-ARS to construct recombinant yeast strains Y-WT and Y-ARS respectively. pPGK and YEpM4 were transformed into D452-2 to construct $\mathrm{Y}-$ Vector as a control strain.

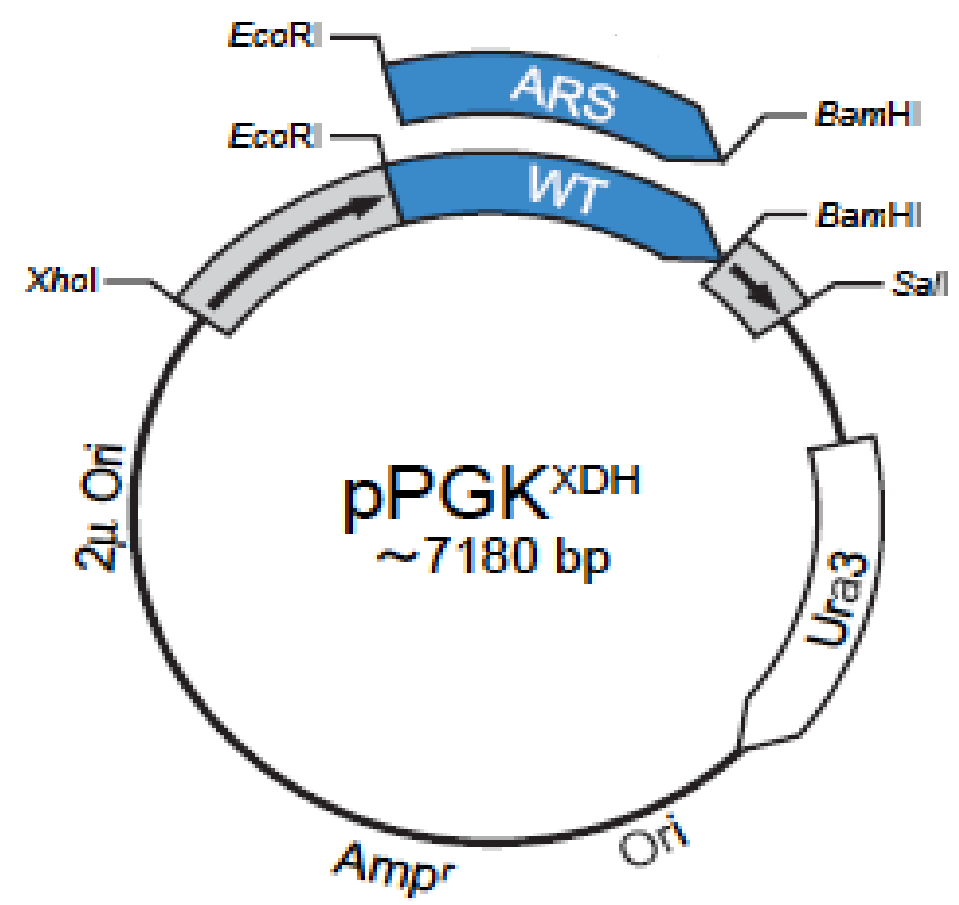

Figure 2 Schematic diagram of yeast expression vector pPGK

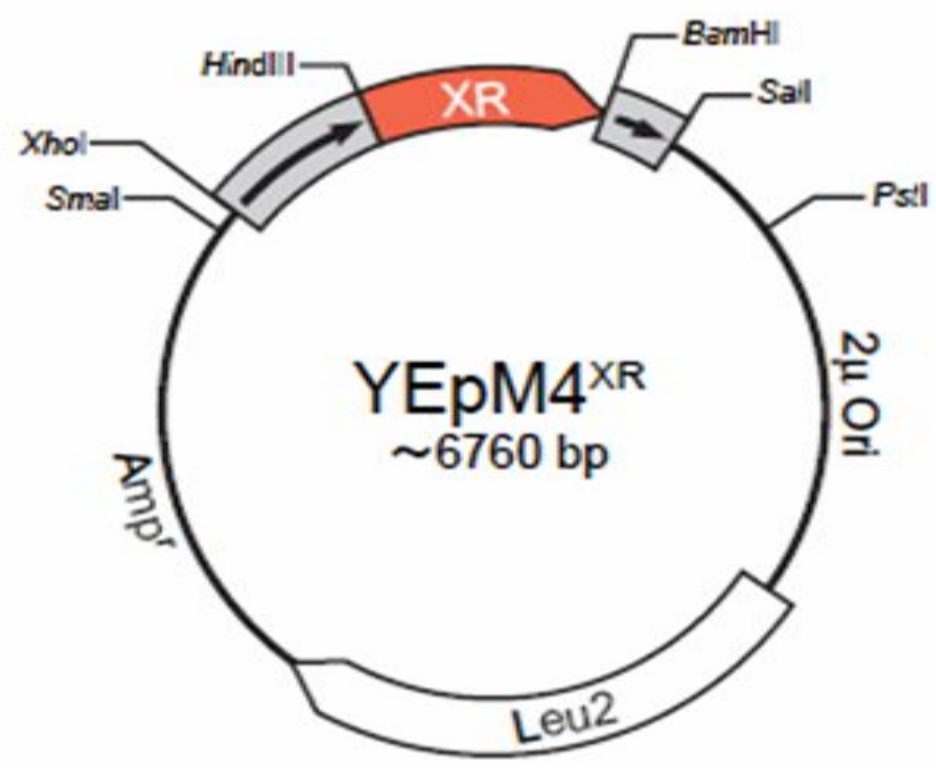

Figure 3 Schematic diagram of yeast expression vector YEpM4 


\subsection{Effect of PsXDH Mutants in S. cerevisiae}

All the recombinant $\mathrm{S}$. cerevisiae strains constructed in this study grew normally in the minimal medium (data not shown). The recombinant strains were cultured in the minimal medium, harvested and then the crude extracts were prepared using glass beads as described in materials and methods. XDH and XR activities in the crude extracts were measured spectrophotometrically. As shown in Fig. 4, Y-ARS showed higher enzyme activity with NADP $^{+}$compared with Y-WT (more than 8-fold higher values of Y-WT). The XR activities in these recombinant yeast were observed at al most the same levels (Table 1). The XDH and $\mathrm{XR}$ activities observed in control strain were probably due to endogenous XDH and XR activities.

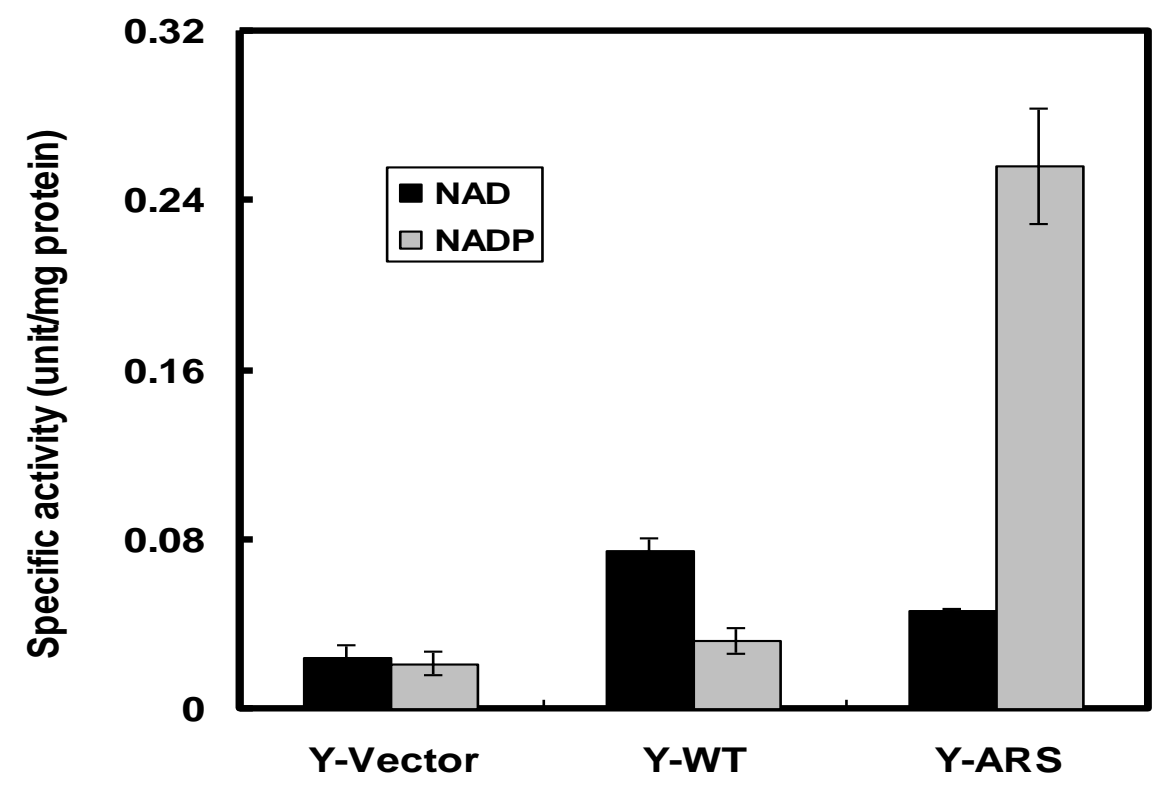

Figure 4 Specific enzyme activities of xylitol dehydrogenase (protein engineered XDH) in the recombinant $S$. cerevisiae were assayed in the direction of polyol oxidation by measuring the reduction of $\mathrm{NAD}^{+}$or $\mathrm{NADP}^{+}$. Values are the means \pm S.D., $\mathrm{n}=3$.

Table 1 Activities of XR and XDH in recombinant yeast strains

\begin{tabular}{lccc}
\hline Strain & XR (unit/mg protein) & \multicolumn{2}{c}{ XDH (unit/mg protein) } \\
\cline { 3 - 4 } & & NAD $^{+}$ & NADP $^{+}$ \\
\hline Y-Vector & $0.010 \pm 0.001$ & $0.024 \pm 0.006$ & $0.022 \pm 0.005$ \\
Y-WT & $0.041 \pm 0.002$ & $0.074 \pm 0.006$ & $0.032 \pm 0.006$ \\
Y-ARS & $0.051 \pm 0.005$ & $0.046 \pm 0.002$ & $0.256 \pm 0.022$ \\
\hline
\end{tabular}




\subsection{Effect of NADP-Preferring XDH Mutant in Ethanol Fermentation}

Ethanol production and xylitol excretion of the recombinant yeasts grown in an incubator with shaker at $30^{\circ} \mathrm{C}$ were measured. One set of fermentation $(100 \mathrm{ml})$ was started with $5 \mathrm{~g} / \mathrm{l}$ glucose and $15 \mathrm{~g} / \mathrm{l}$ xylose (Fig. 5). In case of Y-Vector, an increase of ethanol concentration was found in initial phase $(3-25 \mathrm{~h})$, which may be due to glucose consumption. Y-WT produced ethanol at $2.22 \mathrm{~g} / 1$ and excluded xylitol at $1.42 \mathrm{~g} / 1$. Y-ARS produced the highest amount of ethanol at $2.79 \mathrm{~g} / \mathrm{l}$ and excreted the lowest amount of xylitol at $0.66 \mathrm{~g} / \mathrm{l}$. In all these recombinant yeast strains, glucose was completely fermented in 25 to $40 \mathrm{~h}$. Of the xylose, 25$58 \%$ was fermented in $68 \mathrm{~h}$.

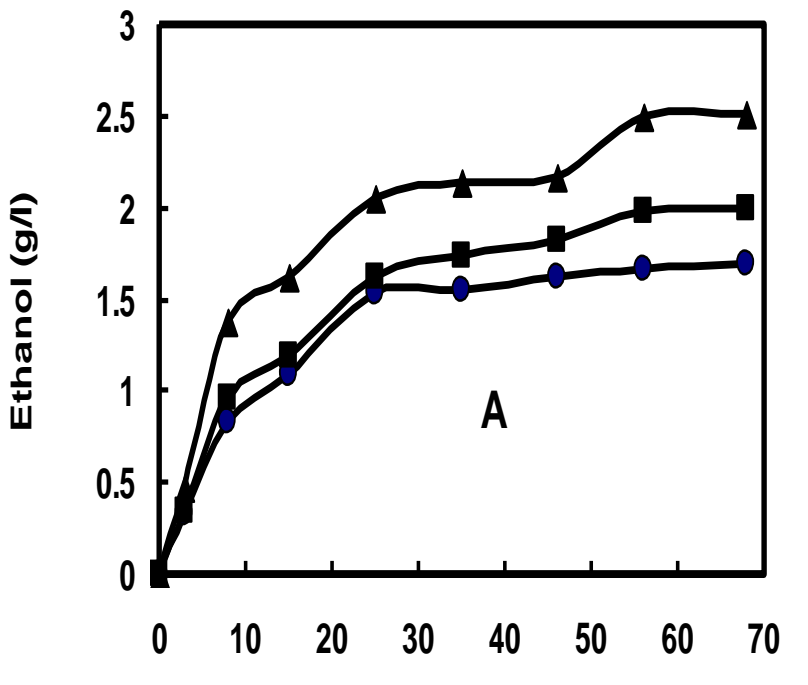

Time (h)

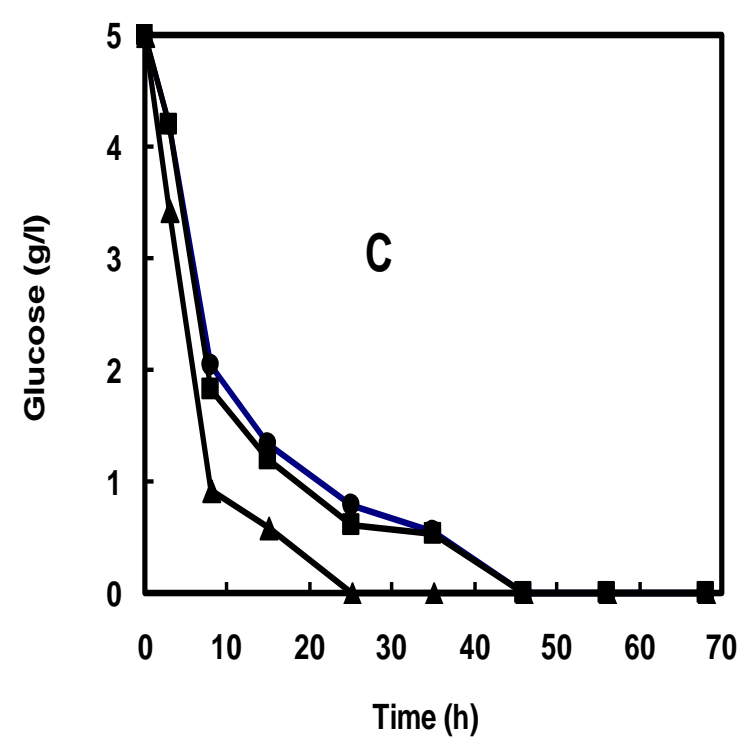

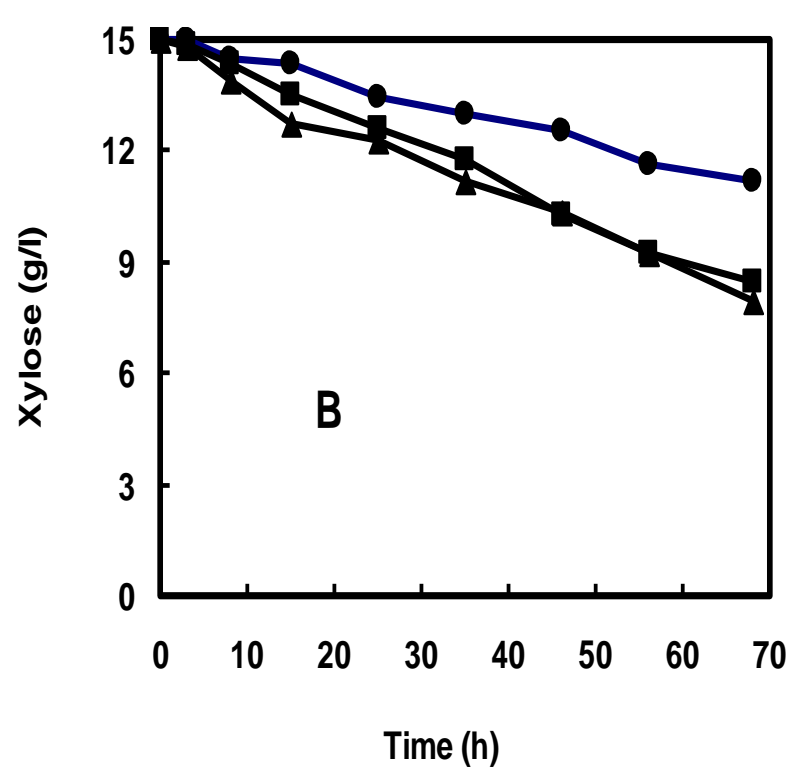

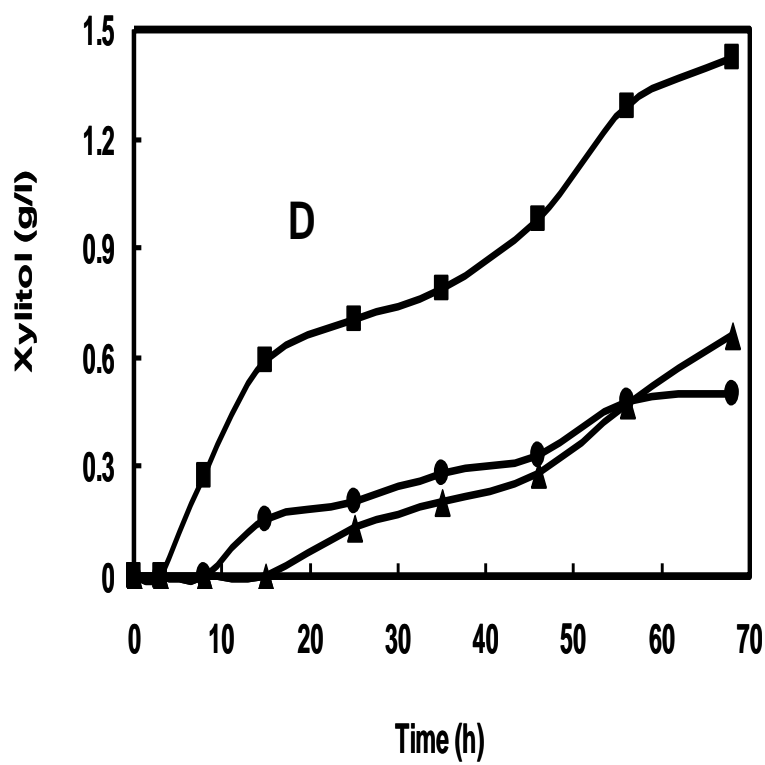

Figure 5 Ethanol fermentation in minimal medium by recombinant $S$. cerevisiae, Y-Vector (circle), Y-WT (square), and Y-ARS (triangle). Concentration of ethanol (A), xylose (B), glucose (C), and xylitol (D) are shown. 
Y-ARS was further investigated in a high performance bioreactor under anaerobic conditions and compared with Y-WT. Y-ARS produced ethanol at $6.88 \mathrm{~g} / 1$ with a yield of $0.45 \mathrm{~g}$ of ethanol/g of total consumed sugars (Fig. 6). The yield of ethanol from consumed sugars reached $88 \%$ of the theoretical yield and xylitol excretion was $0.41 \mathrm{~g} / \mathrm{l}$. Glucose was completely fermented in $15 \mathrm{~h}$. Of the xylose, $68 \%$ was consumed in $72 \mathrm{~h}$. A small amount of glycerol $(0.29 \mathrm{~g} / \mathrm{l})$ and acetic acid $(0.28 \mathrm{~g} / \mathrm{l})$ was produced mainly during the glucose consumption phase. Y-WT produced ethanol at $5.45 \mathrm{~g} / \mathrm{l}$ with a yield of $0.30 \mathrm{~g}$ of ethanol/g of total consumed sugars. The yield of ethanol from consumed sugars reached $60 \%$ of the theoretical yield. The concentration of xylitol excreted $2.66 \mathrm{~g} / \mathrm{l}$. Glycerol $(0.42 \mathrm{~g} / \mathrm{l})$ and acetic acid $(0.38 \mathrm{~g} / \mathrm{l})$ were produced during fermentation. The significant enhancement was found in Y-ARS strain. There was $85 \%$ decrease of unfavorable xylitol excretion and $26 \%$ increase of ethanol production, when compared with the reference strain expressing the wild-type XDH.

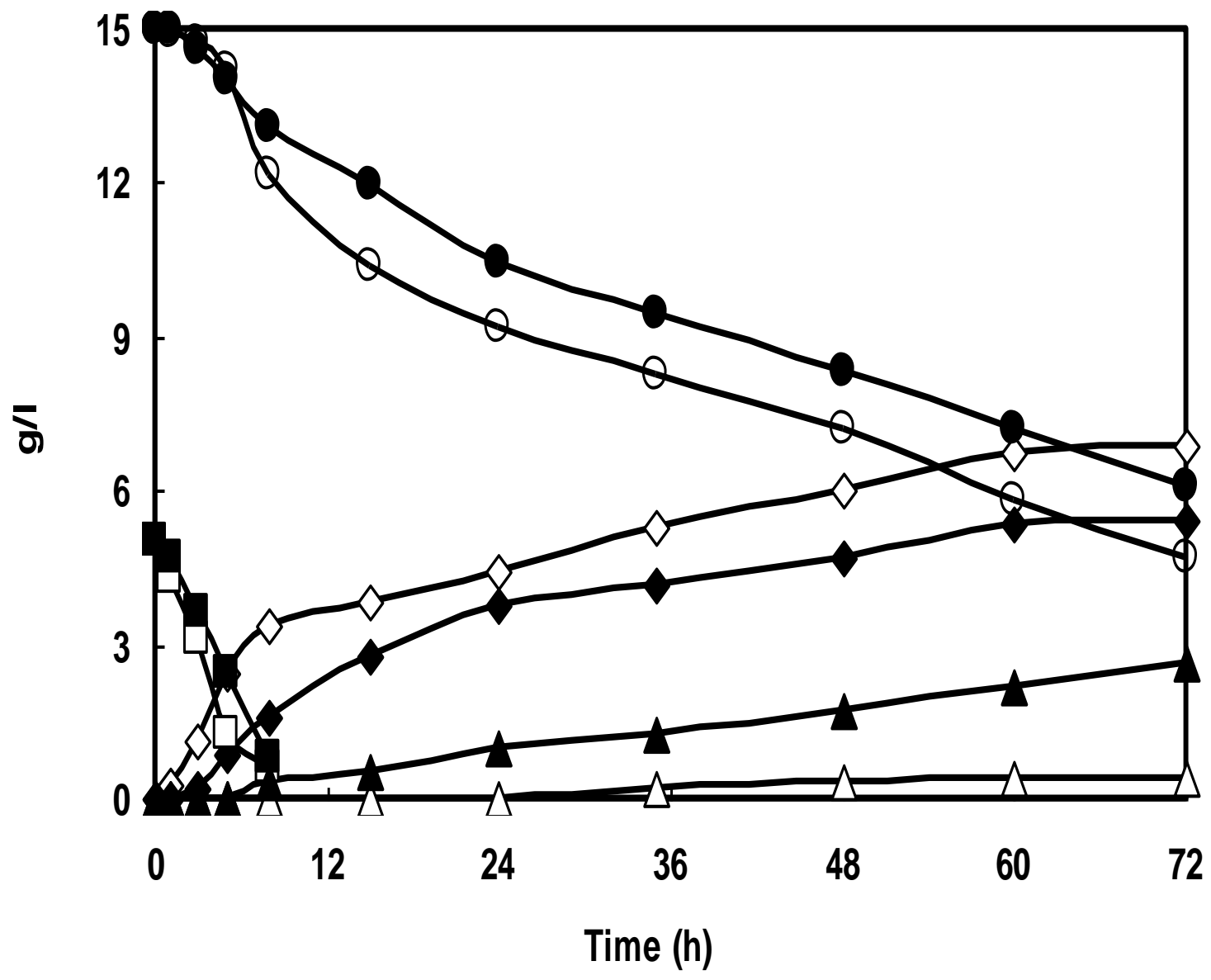

Figure 6 Time dependent xylose (circle) and glucose (square) utilization and ethanol (rhomboid), and xylitol (triangle) concentration profiles of Y-WT (open symbol) and Y-ARS (closed symbol) grown in a bioreactor. Values are the mean of the results of duplicate experiments which differed by less than $10 \%$. Small amount of glycerol and acetic acid were not shown (see in text). 
Most interesting insight in this study is to estimate the effect modifications of PsXDH (in vitro) [16] on fermentation of xylose to ethanol (in vivo). A functional modification of PsXDH in this study is to shift coenzyme specificity toward NADP ${ }^{+}$. ARS mutant shows reversal coenzyme specificity toward $\mathrm{NADP}^{+}$(under coenzyme-saturated condition in vitro) [16]. The $\mathrm{k}_{\mathrm{cat}} / \mathrm{K}_{\mathrm{m}}{ }^{\mathrm{NADP}}$ of ARS dropped 15-fold compared with WT by an increase of $\mathrm{K}_{\mathrm{m}}$ and decrease of $\mathrm{k}_{\text {cat }}$. On the other hand, $\mathrm{k}_{\text {cat }} / \mathrm{K}_{\mathrm{m}}$ NADP increased dramatically (up to 4100 -fold), caused by a large decrease of $\mathrm{K}_{\mathrm{m}}$ value and increase of $\mathrm{k}_{\mathrm{cat}}$, which seems to be due to more efficient fermentation ability in Y-ARS (in particular, decrease of xylitol excretion), compared with Y-WT.

As described in the Introduction, an alternative strategy for maintaining intracellular redox balance is to utilize the xylose-fermenting pathway via XI. Recently, it was first reported that XI from the fungus Piromyces sp. strain E3 resulted in significant activity in $S$. cerevisiae cells [11]. However, comparison of xylose-fermenting ability by XR-XDH- and XI-carrying recombinant $S$. cerevisiae strains revealed that the XR-XDH xylose utilization pathway is much better than the XI pathway [23]. In this study, we introduced only exotic XYL1 and $X Y L 2$ genes into $S$. cerevisiae. On the other hand, in addition to the metabolic engineering described above, the introduction and overexpression of other endogenous genes, including xylulokinase $(X K)$, transketolase (TKL1), transaldolase (TAL1) and several hexose-transporter (HXT1-7) genes, have been attempted to enhance the pentosephosphate pathway and/or xylose uptake [1]. Combined approaches of these strategies and our strategy using the proteinengineered enzyme should be considered to achieve more effective ethanol production from xylose by recombinant $S$. cerevisiae.

\section{CONCLUSIONS}

In this study, the protein engineering was applied to generate enzymes with completely reversed coenzyme specificity and developed recombinant yeasts containing those engineered enzymes for construction of an efficient biomass-ethanol conversion system. A functional modification of PsXDH in this study is to shift coenzyme specificity toward NADP ${ }^{+}$. ARS mutant shows reversal coenzyme specificity toward $\mathrm{NADP}^{+}$(under coenzyme-saturated condition in vitro). The recombinant yeast $\mathrm{Y}$-ARS containing $\mathrm{NADP}^{+}$-dependent mutant ARS was expressed much more highly than each parent enzyme in $S$. cerevisiae cells, similar to in E. coli cells. The significant enhancement was found in Y-ARS strain, in which NADP ${ }^{+}$ dependent $\mathrm{XDH}$ was expressed; $85 \%$ decrease of unfavorable xylitol excretion with $26 \%$ increased ethanol production, when compared with the reference strain expressing the wildtype $\mathrm{XDH}$. In this study, the fermentation medium was prepared using commercial xylose and glucose. Hence future work would be carried out for efficient bioethanol production from mixed sugars (cellulose and hemicelluloses) of agricultural residues by recombinant yeast expressing protein engineered enzyme.

\section{ACKNOWLEDGEMENT}

This work was supported by the Ministry of Education, Science, Sports and Culture, Japan. This work was also supported by Faculty of Engineering, Universiti Malaysia Sarawak, Malaysia. 


\section{REFERENCES}

[1] Jeffries, T.W., and Jin, Y.S. (2004). "Metabolic Engineering for Improved Fermentation of Pentoses by Yeasts.” Appl Microbiol Biotechnol. 63: pp 495-509.

[2] Jeffries, T. W. (1983). "Utilization of Xylose by Bacteria, Yeasts, and Fungi." Adv. Biochem. Eng. Biotechnol. 27: pp 1-32.

[3] Kurtzman, C. P. (1994). "Molecular Taxonomy of the Yeasts." Yeast. 10: pp 17271740.

[4] Jin, Y. S., Lee, T. H., Choi, Y. D., Ryu, Y. W., and Seo, J. H. (2000). "Conversion of Xylose to Ethanol by Recombinant Saccharomyces cerevisiae Containing Genes for Xylose Reductase and Xylitol Dehydrogenase from Pichia stipitis." J. Microbiol. Biotechnol. 10: pp 564-567.

[5] Walfridsson, M., Anderlund, M., Bao, X., and Hahn-Hägerdal, B. (1997). "Expression of Different Levels of Enzymes from the Pichia stipitis XYL1 and XYL2 Genes in Saccharomyces cerevisiae and its Effects on Product Formation during Xylose Utilization.” Appl Microbiol Biotechnol. 48: pp 218-224.

[6] Verduyn, C., Van Kleef, R., Frank, J., Schreuder, H., Van Dijken, J. P., and Scheffers, W. A. (1985). "Properties of the NAD(P)H-Dependent Xylose Reductase from the Xylose-Fermenting Yeast Pichia stipitis." Biochem. J. 226: pp 669-677.

[7] Rizzi, M., Harwart, K., Erlemann, P., Buithanh, N. A., and Dellweg, H. (1989). "Purification and Properties of the NAD"-Xylitol-Dehydrogenase from the Yeast Pichia stipitis." J. Ferment. Bioeng. 67: pp 20-24.

[8] Chiang, L.-C., Gong, C.-S., Chem, L.-F., and Tsao, G. T. (1981). "D-Xylulose Fermentation to Ethanol by Saccharomyces cerevisiae." Appl. Environ. Microbiol. 42: pp 284-289.

[9] Tantirungkij, M., Izuishi, T., Seki, T., and Yoshida, T. (1994). "Fed-Batch Fermentation of Xylose by a Fast-Growing Mutant of Xylose-Assimilating Recombinant Saccharomyces cerevisiae.” Appl. Microbiol. Biotechnol. 41: pp 8-12.

[10] Walfridsson, M., Bao, X., Anderlund, M., Lilius, G., Bulow, L., and Hahn-Hägerdal, B. (1996). "Ethanolic Fermentation of Xylose with Saccharomyces cerevisiae Harboring the Thermus thermophilus xylA Gene, which Expresses an Active Xylose (glucose) Isomerase". Appl. Envir. Microbiol. 62: pp 4648-4651.

[11] Kuyper, M., Harhangi, H.R., Stave, A.K., Winkler, A.A., Jetten, M.S., de Laat, WT., den Ridder, J.J., Op den Camp, H.J., van Dijken, J.P., and Pronk, J.T. (2003). "HighLevel Functional Expression of a Fungal Xylose Isomerase: The Key to Efficient Ethanolic Fermentation of Xylose by Saccharomyces cerevisiae?' FEMS Yeast Res. 4(1): pp 69-78.

[12] Ho, N.W.Y., Chen Z., and Brainard A.P. (1998). "Genetically Engineered Saccharomyces Yeast Capable of Effective Cofermentation of Glucose and Xylose". App Environ Microbiol. 64: pp1852-1859.

[13] Eliasson, A., Christensson, C., Wahlbom, F.C., and Hahn-hägendal, B. (2000). "Anaerobic Xylose Fermentation by Recombinant Saccharomyces cerevisia Carrying XYL1, XYL2, and XKS1 in Mineral Medium Chemostat Cultures.” App Environ Microbiol. 66(8): pp 3381-3386.

[14] Jeppsson, M., Bengtsson, O., Franke, Katja., Lee, H., Hahn-Hägerdal, B., and GorwaGrauslund, M.F. (2006). "The Expression of a Pichia stipitis Xylose Reductase Mutant with Higher $\mathrm{K}_{\mathrm{M}}$ for NADPH Increases Ethanol Production from Xylose Recombinant Saccharomyces cerevisiae." Biotechnol Bioeng. 93: pp 665-673. 
[15] Metzger, M.H., and Hollenberg, C.P. (1995). "Amino Acid Substitutions in the Yeast Pichia stipitis Xylitol Dehydrogenase Coenzyme-Binding Domain Affect the Coenzyme Specificity.” Eur J Biochem. 228(1): pp 50-54.

[16] Watanabe, S., Kodaki, T., and Makino, K. (2005). "Complete Reversal of Coenzyme Specificity of Xylitol Dehydrogenase and Increase of Thermostability by the Introduction of Structural Zinc." J. Biol. Chem. 280: pp 10340-10349.

[17] Kurztman, C.P., (1994). "Molecular Taxonomy of the Yeasts. Yeast". 10: pp17271740 .

[18] Gietz, D., Jean, A.S., Woods, R.A., and Schiestl, R.H. (1992). "Improved Method for High Efficiency Transformation of Intact Yeast Cells.". Nucleic Acids Research. 20(6): pp 1425.

[19] Lowry, O.H., Rosebrough, N.J., Farr, A.L., and Randall, R.J. (1951). "Protein Measurement with the Folin Phenol Reagent.” J. Biol. Chem. 193: pp 265 - 275.

[20] Kang, Y. S., Kane, J., Kurjan, K., Stadel, J. M., and Tipper, D. J. (1990). Effects of Expression of Mammalian G $\alpha$ and Hybrid Mammalian-Yeast G $\alpha$ Proteins on the Yeast Pheromone Response Signal Transduction Pathway." Mol. Cell. Biol. 10: pp 25822590 .

[21] Amore, R., Kötter, P., Kuster, C., Ciriacy, M., and Hollenberg, C. P. (1991). "Cloning and expression in Saccharomyces cerevisiae of the NAD $(\mathrm{P}) \mathrm{H}-\mathrm{dependent}$ Xylose Reductase-Encoding Gene xyll from the Xylose-Assimilating Yeast Pichia stipitis. Gene." 109: pp 89-97.

[22] Nikawa, J., sass, P., and Wigler, M. (1987). "Cloning and Characterization of the Low-Affinity Cyclic AMP Phosphodiesterase Gene of Saccharomyces cerevisiae." Mol. Cell. Biol. 7: pp 3629-3636.

[23] Karhumaa, K., Sanchez, R. G., Hahn-Hägerdal, B., and Gorwa-Grauslund, M. F. (2007). "Comparison of the xylose reductase-xylitol dehydrogenase and the xylose isomerase pathways for xylose fermentation by recombinant Saccharomyces cerevisiae". Microb Cell Fact”, 6: pp 5. 